\title{
Prevalence of anemia $\&$ its association with various risk factors in slum dwelling adolescent girls of Raipur city
}

\author{
Phuljhele $\mathbf{S}^{1}$, Dash $\mathbf{S}^{2}$, Beck $\mathbf{P}^{3}$, Kurrey $\mathbf{V K}^{4}$ \\ ${ }^{1}$ Dr Sharja Phuljhele, Associate Professor, Department of Paediatrics, ${ }^{2}$ Dr Snigdha Dash, Post graduate student, ${ }^{3}$ Dr \\ Pratima Beck, Associate Professor, Department of Paediatrics, ${ }^{4}$ Dr Virendra K Kurrey, Associate Professor. All are \\ affiliated with Pt JNM Medical College, Raipur, CG, India
}

Address for correspondence: Dr Sharja Phuljhele, Email: sharjaphuljhele@ gmail.com

\begin{abstract}
Abstret
Introduction: Adolescent girls are at high risk for anemia and malnutrition, which can have serious consequences throughout the reproductive years of life in the form of high maternal mortality, low birth weight babies and perinatal mortality. Since much, less attention paid to this age group and there is paucity of data to represent the magnitude of this problem so we have conducted this study. Methods: This cross sectional observational study conducted in 385 adolescent girls in slums of Raipur city. Various socio-demographic factors, physical growth and nutritional status of the adolescent girls were assessed by anthropometric indices. Anemia detected by Sahli's method. Data analyzed by appropriate statistical method, to find out the significance of association between various attributes. Result: Majority of girls were vegetarians (54.54\%). $57.66 \%$ were undernourished. Anemia found in $61.03 \%$ cases out of which mild anemia was in $45.19 \%$ and moderate in $13.50 \%$. A statistically significant association found between anemia and status of menarche, diet, nutritional status and education of mother. Conclusion: Majority of adolescent girls was suffering from mild anemia, which can be prevented by modification of diet, nutrition and other socio-demographic risk factors. This may require meticulous implementation of nutrition programmes and focus toward adolescent health.
\end{abstract}

Key words: Adolescent Girls, Anemia, Nutritional Status, Urban Slums

\section{Introduction}

Adolescence as a term was first used in West in 15th century and was derived from Latin word 'adolescere' that means, "Growing into maturity" [1]. It is recommended that it would be most appropriate to consider adolescents between 10-19 years of age [2].

In India, adolescent girls, who constitute a substantial segment of its population form a vulnerable group [3]. Adolescence is a susceptible period when nutritional needs increase due to the somatic growth spurt [4]. In females it is characterised by beginning of the menstrual cycle or reproduction. Adolescent female are at a high risk for nutritional deficiency. Insufficient nourishment during adolescence can have serious consequences all over the reproductive years of life and beyond [5].

Manuscript received: $30^{\text {th }}$ Aug 2015

Reviewed: $7^{\text {th }}$ Sept 2015

Author Corrected: $18^{\text {th }}$ Sept 2015

Accepted for Publication: $25^{\text {th }}$ Sept 2015
The nutritional anemia in adolescent girls attributes to the increase maternal mortality rate, the elevated occurrence of low birth weight babies, perinatal mortality [6]. This period of life is also vital due to control of anemia in pregnant women can be acquired by satisfactory iron store. Adolescence, one of the nutritional hassle periods of life comes with increased needs for energy, protein, minerals and vitamins [7]. Augmented physical activity with poor intake habits and the beginning of menstruation contributes to accentuating the impending risk for adolescent's malnutrition [8]. Anthropometric measurements can be used to monitor changes in growth of adolescents. Raipur, the capital city of Chhattisgarh approximately $50 \%$ of its population living in slums with sex ratio of 946 females per 1,000 males and total estimated population living in slum was $5,16,829$ with 56,851 adolescent females[9].

Most of the health problems encountered in adolescents are preventable and curable if detected in early stages of 
development. Therefore, this study intended to assess the extent of problem of anemia in adolescent females along with various socio-demographic factors in urban slum.

\section{Material \& Methods}

Study Design -This Cross sectional observational analytical community based study carried out from July 2012 to July 2013 among adolescent girls selected from slums located in Raipur city. Raipur Municipal Corporation recorded 282 slums in Raipur out of which, 15 slums chosen for study purpose by systematic random sampling with the help of table of random number.

Sample size [10] was based on the extent of anemia in adolescent females and calculated by using the WHO Sample Size Calculator for estimating a population proportion for specified absolute precision by the following formula.

\section{$\mathrm{n}=\mathrm{Z}^{2}{ }_{(1-\alpha)} / \mathrm{s} \mathrm{P}(1-\mathrm{P}) / \mathrm{d}^{2}$}

Where, $\mathrm{n}=$ the estimated sample size, $\mathrm{P}=$ anticipated population proportion $(0.50), \mathrm{d}=$ absolute precision required (0.05), $1-\alpha=$ confidence level taken as $95 \%$ for which $\mathrm{Z}=1.96$. Thus, the estimated sample size in this study is 385 .

Inclusion criteria - All defined adolescent (10-19 years) girls of slum area.

Exclusion criteria - (i) Chronic systemic illness of $\geq 6$ weeks duration (Tuberculosis, Thyroid disorders, Diabetes, Heart disease, Malignancy)

(ii) Any major surgery affecting anthropometric indices

(iii) Bed ridden \& debilitated patients

(iv) Any orthopaedic problem affecting anthropometry (polio, spinal injury/TB, diseases of hip affecting limb length).

Study was started after clearance from institutional ethical committee. Informed consent obtained from those who were less than 18 years of age. With the help of local health worker a cross sectional survey was done by door to door visit. Examinations were conducted at local Anganwadi centre. For categorizing cases in different socioeconomic status, Modified B. G. Prasad's classification (2008) was used. The subjects were interrogated through predesigned questionnaire prepared carefully and Data collected on a predesigned $\&$ pretested proforma.

The age of menarche determined by recall method. The questions pertaining to menstrual problems, regularities of menses and dysmenorrhoea were collected followed by detailed general examination regarding state of health and later by complete systemic examination.

Measurement of anthropometric variables: For evaluation of growth \& nutritional status, anthropometric measurements like weight $\&$ height was measuring for each adolescent and BMI calculated from the recorded values. Weight measured using a bathroom scale after eliminating zero error with minimal clothing and without shoes to the nearest 100 grams. Height assessed in centimetres by marking on a wall with the help of a measuring tape. BMI calculated from the weight and height of the individual for various ages to assess the nutritional status as per the recent WHO Standard growth charts. Age specific BMI considered as a specific indicator to assess under nutrition. WHO currently recommends using BMI for age compared to reference standard and defines under nutrition as $<5$ th percentile of BMI for age.

Estimation of anemia: Anaemia assessed by estimation of haemoglobin by Sahli's method using a hemoglobinometer.

WHO standard for classification of Anemia [11]

Normal hemoglobin: $\geq 12 \mathrm{gm} / \mathrm{dl}$

Mild anemia: $10-<12 \mathrm{gm} / \mathrm{dl}$

Moderate anemia: $7-<10 \mathrm{gm} / \mathrm{dl}$

Severe anemia: $<7 \mathrm{gm} / \mathrm{dl}$

Analysis of Data - Chi-squire test applied for statistical analysis, to find out the significance of association between various attributes using Microsoft Office Excel 2007 and Graph Pad Insta software.

\section{Results}

Demographical, clinical and socio-economic characteristics: Out of 385 studied adolescent girls between 10-19 years, the mean age was 14.2 years. The maximum number of girls belonged to socioeconomic Class V [5] (80\%) followed by Class IV (17.66\%) and least to Class III (only 2.31\%). None of the cases belonged to Class Class II or I. The literacy rate in fathers was $67.79 \%$, of which majority $(41.81 \%)$ had received only primary education. On the other hand, the literacy 
rate in mothers was very low $(45.19 \%)$, out of which $34.54 \%$ had received only primary education. All the girls were literate.

\begin{tabular}{|l|l|l|l|l|l|}
\hline \multicolumn{7}{|l|}{ Table 1- Distribution of Cases According to Degree of Anemia } \\
\hline Anemia & No. of cases & $\%$ & Proportion & SEP & 95\% C.I. \\
\hline No anemia & 150 & 38.96 & 0.389 & 0.024 & $0.341-0.437$ \\
\hline Mild & 174 & 45.19 & 0.451 & 0.025 & $0.402-0.500$ \\
\hline Moderate & 52 & 13.50 & 0.135 & 0.030 & $0.076-0.194$ \\
\hline Severe & 9 & 2.34 & 0.023 & 0.007 & $0.008-0.038$ \\
\hline
\end{tabular}

Majority of our study cases were vegetarians (54.54\%) out of which $47.27 \%$ were having anemia whereas, out of $45.45 \%$ non-vegetarians only $13.76 \%$ were anemic.The average weight was $69.4 \%$ of the $50^{\text {th }}$ percentile of the NCHS standard. All the girls were underweight with a mean weight of $33.01 \pm 6.14 \mathrm{~kg}(\mathrm{CI}=32.39-33.62)$. When compared with the standard WHO reference charts, the average height was $92.45 \%$ of the $50^{\text {th }}$ percentile. None of the girls in our study were stunted (height $<3^{\text {rd }}$ percentile of WHO standard). Mean height was $144.64 \pm 8.6 \mathrm{~cm}(\mathrm{CI}=143.78-145.50 \mathrm{~cm}) . \mathrm{In}$ our study, $57.66 \%$ of total cases were having undernutrition with a mean BMI of $15.61 \pm 1.42 \mathrm{~kg} / \mathrm{m}^{2}(\mathrm{CI} 15.46-15.75)$.

The menstrual pattern of the girls studied and out of 385 cases, 213 girls (55.32\%) had attained menarche. The mean age of attending menarche was $12.92 \pm 0.96$ years. Anemia was seen in $37.14 \%$ girls who have achieved menarche as compared to $23.89 \%$ girls without menarche. Out of 385 study subjects, 235 cases $(61.03 \%)$ were anemic. The sample mean of hemoglobin calculated to be $11.29 \pm 1.48 \mathrm{~g} / \mathrm{dl}$. Mild anemia $(\mathrm{Hb}=10-<12 \mathrm{~g} / \mathrm{dl})$ was seen in 45.19 cases followed by moderate anemia $(\mathrm{Hb}=7-<10 \mathrm{~g} / \mathrm{dl})$ in $13.50 \%$. Only nine cases $(2.34 \%)$ of severe anemia $(\mathrm{Hb}<7 \mathrm{~g} / \mathrm{dl}) \mathrm{had}$ been identified.

Statistical analysis: Chi-square test was applied to find the association between status of menarche and Body mass index which was found to be statistically significant $(\mathrm{p}<0.05)$. A statistically significant association $(\mathrm{p}<0.05)$ was found between anemia and status of menarche, diet, Body mass index and education of mother but not with other sociodemographic factors like age and socio-economic status.

\begin{tabular}{|c|c|c|c|c|c|c|c|}
\hline Factors & $\begin{array}{l}\text { Anemia } \\
\text { present }\end{array}$ & $\begin{array}{l}\text { No } \\
\text { anemia }\end{array}$ & Chi-sq & df & $P$ value & $\begin{array}{l}\text { Odd's } \\
\text { Ratio }\end{array}$ & $95 \%$ CI of OR \\
\hline \multicolumn{8}{|l|}{ 1.Menarche } \\
\hline Attained & 143 & 71 & \multirow[t]{2}{*}{6.24} & \multirow[t]{2}{*}{1} & \multirow[t]{2}{*}{0.0125} & \multirow[t]{2}{*}{1.729} & \multirow[t]{2}{*}{$1.14-2.61$} \\
\hline Not attained & 92 & 49 & & & & & \\
\hline \multicolumn{8}{|l|}{ 2. Diet } \\
\hline Vegetarian & 182 & 28 & \multirow[t]{2}{*}{125.23} & \multirow[t]{2}{*}{1} & \multirow[t]{2}{*}{$<0.0001$} & \multirow[t]{2}{*}{14.962} & \multirow[t]{2}{*}{$8.965-24.973$} \\
\hline Non-vegetarian & 53 & 122 & & & & & \\
\hline \multicolumn{8}{|c|}{ 3.Mother's Literacy } \\
\hline Illiterate & 137 & 74 & \multirow{4}{*}{18.371} & \multirow{4}{*}{8} & \multirow{4}{*}{0.018} & \multirow{4}{*}{ - } & \multirow{4}{*}{-} \\
\hline Primary (1-5) & 84 & 49 & & & & & \\
\hline Middle (6-8) & 12 & 14 & & & & & \\
\hline $\operatorname{High}(9-12)$ & 2 & 13 & & & & & \\
\hline \multicolumn{8}{|l|}{ 4. Age } \\
\hline Early & 105 & 80 & \multirow{3}{*}{2.8} & \multirow{3}{*}{6} & \multirow{3}{*}{0.8335} & \multirow{3}{*}{ - } & \multirow{3}{*}{ - } \\
\hline Middle & 59 & 33 & & & & & \\
\hline Late & 71 & 37 & & & & & \\
\hline \multicolumn{8}{|c|}{ 5. Socioeconomic Status } \\
\hline III & 3 & 6 & \multirow{3}{*}{4.157} & \multirow{3}{*}{6} & \multirow{3}{*}{0.6555} & \multirow{3}{*}{ - } & \multirow{3}{*}{ - } \\
\hline IV & 38 & 30 & & & & & \\
\hline V & 194 & 114 & & & & & \\
\hline
\end{tabular}


Table- 3 shows the association of Body mass index (BMI) with anemia which was found to be extremely significant $(\mathrm{p}<0.0001)$ in adolescent with BMI $<5^{\text {th }}$ percentile. Similar results were seen with the other study $[21,27]$.

\begin{tabular}{|l|l|l|l|l|l|l|l|}
\hline Table 3 Association of BMI With Anemia \\
\hline Factors & $\begin{array}{l}\text { Anemia } \\
\text { present }\end{array}$ & $\begin{array}{l}\text { No } \\
\text { anemia }\end{array}$ & df & Chi-sq & P value & $\begin{array}{l}\text { Odd's } \\
\text { Ratio(OR) }\end{array}$ & 95\% CI of OR \\
\hline BMI & 195 & 27 & 1 & $\mathbf{1 5 5 . 7}$ & $<\mathbf{0 . 0 0 0 1}$ & 22.208 & $12.968-38.031$ \\
\hline$<5^{\text {th }}$ percentile & 40 & 123 & & & \\
\hline $5^{\text {th }}-84^{\text {th }}$ percentile & 40 &
\end{tabular}

\section{Discussion}

In our study, out of 385 study subjects, 235 cases $(61.03 \%)$ were anaemic. Other studies have similar results [12-18]. National Family Health Survey (NFHS) $3[18]$ estimates revealed the prevalence of anemia to be $65-75 \%$ in adolescent girls. WHO/ UNICEF has suggested that the problem of anemia is of very high magnitude in a community when the prevalence rate exceeds $40 \%$ [19]. This shows that the problem of iron deficiency in these girls with prevalence of $61 \%$ should be considered serious and action should be taken immediately.

Chi-square test applied for statistical analysis to find the significance of association between various attributes. Table 2 shows a statistically significant association between anemia and status of menarche, diet, Body mass index and education of mother $(\mathrm{p}<0.05)$ but not with other socio-demographic factors like age and socioeconomic status $(\mathrm{p}>0.05)$.

Rekha dutt et al [16], Kaur S.et al[17],Verma A. et al [20], found that compared to non vegetarians, more vegetarians were anemic similar to our study. Other studies [21,22,23] found no association between age of girl and anemia similar to our study. Rajaratnam Jolly et al [24] also found significant association between anemia in girls who had attained menarche and mother's literacy status. Chaudhary S.M. et al[25] found significant association between mother's literacy and anemia among adolescent girls similar to our study. Shilpa S. Biradar et al[26] found a significant association of anemia with the socio-economic status. The prevalence of anaemia was high in girls who belonged to the low socio-economic status. This was different from the result obtained from our study because majority of girls in our study belonged to low socioeconomic status and so a causal relationship could not be established.

\section{Conclusion}

In our study, majority of girls were suffering from mild anemia, which can be prevented by modification of diet, nutrition and other socio-demographic risk factors. This may require rigorous implementation of nutrition programmes and adolescent health services by the government. Further studies should be conducted in urban slums to assess the magnitude of this problem in various parts of the country.

Conflict of interest: None declared.

Funding: Nil, Permission from IRB: Yes

\section{References}

1. Bhave, Swathi Y., M. K. C. Nair, and A. Parthasarathy. Bhave's textbook of adolescent medicine. New Delhi: Japee Brothers, 2006, 2006.

2. Bezbaruah, S., \& Janeja, M. K. (2000). Adolescents in India, a Profile. UNFPA for UN system in India.

3. Chaudhary, SM, and Vasant R. Dhage. A study of anemia among adolescent females in the urban area of Nagpur . Indian J Community Med. 2008 Oct; 33(4): 243-245. doi: 10.4103/0970-0218.43230.

4. Gupta, S. Adolescence-The Trouble Years in a Girl's Life. (1990).

5. Koushik, Nalluri Kranthi, et al. Prevalence of anaemia among the adolescent girls: a three months cross-sectional study. Women 14.16 (2014): 12-16.

6. . Kaur, S., P. R. Deshmukh, and B. S. Garg. Epidemiological correlates of nutritional anemia in adolescent girls of rural Wardha. Indian Journal of Community Medicine Vol. 31, No. 4, OctoberDecember, 2006:255-258. 
7. Kapil U, Manocha S, Bhasin S. Dietary intake amongst 'well to do' adolescent boys and girls in Delhi. Indian Pediatr. 1993 Aug;30(8):1017-9.

8. Parimalavalli, R., and M. Sangeetha. Anthropometric measurements and nutrient intake of adolescent girls. Anthropologist 13.2 (2011): 111-115.

9. Goswami, Sribas. Health and Child Development Paradox: Findings from Raipur Slums. Global Journal of Human-Social Science Research 12.14-C (2012).

10. Lwanga, Stephen Kaggwa, and Stanley Lemeshow. Sample size determination in health studies: a practical manual. (1991).

11. DeMaeyer, Edouard M., et al. Preventing and controlling iron deficiency anaemia through primary health care: a guide for health administrators and programme managers. (1989).

12. Rana, T. Age at menarche-Nutritional status and other associated factors in urban Hyderabad girls. Diss. Ph. D. Thesis. Submitted to National Institute of Nutrition, Hyderabad, 1983.

13. Dixit, Swati, Surya Kant, G C Agarwal, J V Singh. A community based study on prevalence of anaemia among adolescent girls and its association with iron intake and their correlates. Ind $\mathbf{J}$ Prev Soc Med 2011;42(4):393-398.

14.Singh N, Mishra CP. Nutritional status of adolescent girls of a slum community of Varanasi. Indian J Public Health. 2001 Oct-Dec;45(4):128-34.

15. Kalamka, H. S. Study of health problems of Adolescents in urban field practice area. Dept. of Preventive \& Social Medicine, Indira Gandhi Medical College, Nagpur (2001).

16.Rawat CM, Garg SK, Singh JV, Bhatnagar M, Chopra H, Bajpai SK. Prevalence of anaemia among adolescent girls in rural area of District Meerut, U.P. Indian J Public Health. 2001 Jan-Mar;45(1):24-6.

17. Kaur, S., P. R. Deshmukh, and B. S. Garg. Epidemiological correlates of nutritional anemia in adolescent girls of rural Wardha. Indian Journal of
Community Medicine Vol. 31, No. 4, OctoberDecember, 2006:255-258

18. Suryakantha, A. H. Community Medicine with Recent Advances, Jaypee Brothers Medical Publishers (P) Ltd. New Delhi (2009): 646-647.

19. Sharma, M K., D K. Walia, and N. K. Goel. Micronutrient deficiency in pre-school rural, urban \& slum children of field practice area of a tertiary care hospital. Indian J. Prev. Soc. Med 43.1 (2012).

20. Verma, A., et al. Factors influencing Anaemia among girls of school going age (6-18 years) from the slums of Ahmedabad city. Indian Journal of Community Medicine 2004;29(1): 25-26.

21. Kulkarni, Meenal Vinay, P. M. Durge, and N. B. Kasturwar. Prevalence of anemia among adolescent girls in an urban slum. National Journal of Community Medicine 2012;3(1): 108-111.

\section{Bulliyy G, Mallick G, Sethy GS, Kar SK.}

Hemoglobin status of non-school going adolescent girls in three districts of Orissa, India.Int J Adolesc Med Health. 2007 Oct-Dec;19(4):395-406.

23. Vinod Wasnik, B. Sreenivas Rao, Devkinandan Rao. A study of the health status of early adolescent girls residing in social welfare hostels in Vizianagaram district of Andhra Pradesh State, India. International Journal of Collaborative Research on Internal Medicine and Public Health 2012;4(1): 71-83.

24.Rajaratnam J, Abel R, Asokan JS, Jonathan P. Prevalence of anemia among adolescent girls of rural Tamilnadu. Indian Pediatr. 2000 May;37(5):532-6.

25. Chaudhary, SM, and Vasant R. Dhage. A study of anemia among adolescent females in the urban area of Nagpur . Indian J Community Med. 2008 Oct; 33(4): 243-245. doi: 10.4103/0970-0218.43230.

26. Biradar, Shilpa S. et al. Prevalence of anaemia among adolescent girls: a one year cross-sectional study. Journal of Clinical and Diagnostic Research. 2012 May (Suppl-1), Vol-6(3):372-377.

27. M KALHAN, B Vashisht, V kumar, S Sharma. Nutritional Status of adolescent girls of rural 


\section{How to cite this article?}

Phuljhele S, Dash S, Beck P, Kurrey VK. Prevalence of anemia \& its association with various risk factors in slum dwelling adolescent girls of Raipur city. Int J Med Res Rev 2015;3(9):1064-1069. doi: 10.17511/ijmrr.2015.i9.194. 